\title{
Effects of Vowel Length on Gaze Durations in Silent and Oral Reading
}

\author{
Lynn Huestegge \\ RWTH Aachen University
}

\begin{abstract}
Vowel length is known to affect reaction times in single word reading. Eye movement studies involving silent sentence reading showed that phonological information of a word can be acquired even before it is fixated. However, it remained an open question whether vowel length directly influences oculomotor control in sentence reading. In the present eye tracking study, subjects read sentences that included target words of varying vowel length and frequency. In Experiment 1, subjects read silently for comprehension, whereas Experiment 2 involved oral reading. Experiments 3 and 4 additionally included an articulatory suppression task and a foot tapping task. Results indicated that in conditions that did not require additional articulation (Experiments 1 and 4) gaze durations were increased for words with long vowels compared to words with short vowels. Conditions that required simultaneous articulation (Experiments 2 and 3 ) did not yield a vowel length effect. The results point to an influence of phonetic properties on oculomotor control during silent reading around the time of the completion of lexical access.
\end{abstract}

Keywords: Vowel length, Reading, Eye Movements, Dual Task, Articulatory Suppression, Foot Tapping, Silent reading, Oral reading

\section{Introduction}

During silent reading, we often subjectively experience the presence of inner speech. Already at the beginning of the $20^{\text {th }}$ century, Huey $(1908 / 1968)$ stressed the importance of this phenomenon for understanding information processing during reading (see also Brown, 1958; Egger, 1904). He stated that phonological representations are auditory in nature, like a voice in the head rather than an abstract code of phonological parameters (e.g., Fodor, 1998; Fredriksen \& Kroll, 1976; McCusker, Hillinger, \& Bias, 1981; Meyer, Schvaneveldt, \& Rudy, 1974; Spoehr \& Smith, 1971). In scientific terms, the notion of inner speech implies that reading a word activates phonetically informed representations which are similar in structure to the pronunciation of the word. The present study addresses the question of whether phonetic properties of words inform the word identification process by testing whether vowel length influences oculomotor control in silent and oral reading.

Studies involving the identification of isolated words convincingly demonstrated that phonological information is activated during silent reading (Berent \& Perfetti,
1995; Drieghe \& Brysbaert, 2002; Folk, 1999; Lee, Binder, Kim, Pollatsek, \& Rayner, 1999; Lukatela \& Turvey, 1994; Perfetti \& Bell, 1991; Rayner, Pollatsek, \& Binder, 1998; Van Orden, 1987; Ziegler, Ferrand, Jacobs, Rey, \& Grainger, 2000). However, there is disagreement to what extent phonological information resembles inner speech. While some studies reported evidence that phonological representations are to a large extent similar to speech (Klapp, 1971; McCutchen \& Perfetti, 1982), the main view in linguistic theory assumes that lexical representations of a word do not include phonetic information, but rather abstract phonological codes (linear generative phonology, see Chomsky \& Halle, 1968; Kenstowicz \& Kisserberth, 1979).

Abramson and Goldinger (1997) examined the influence of phonetic information on phonological representations more closely. They compared lexical decision times for words of equal orthographic length that differ, when spoken, in vowel length. Responses were generally slower for phonetically long (vs. short) stimuli. This vowel length effect was more pronounced for words of low (vs. high) lexical frequency. The authors concluded that silent reading indeed activates inner speech during lexical processing, a phenomenon that has later been termed "phonetically informed phonology" (Lukatela, 
Eaton, Sabadini, \& Turvey, 2004). These results are clearly inconsistent with theoretical accounts in which lexical access solely relies on a visual or an abstract phonological code, since for example the words "plead" and "pleat" are identical in the number of letters, the frequency of occurrence, and the number of phonemic segments. Within the framework of generative linear phonology only the surface form that is derived from the abstract phonological form contains phonetic information, but the generation of such a surface form would be a post-lexical and not a lexical process. Alternative theories of phonology, like gestural phonology (e.g., Browman \& Goldstein, 1995), attempt to close the categorical gap between phonology and phonetics by highlighting the role of movement patterns of vocal tract articulators (gestures). Within such a framework the lexical entry of a word is close to a specific gesture pattern that produces a corresponding acoustic form. Thus, gestural phonology was proposed as an adequate unitary framework to redescribe the effects of a phonetically informed phonology (Lukatela et al., 2004).

Lukatela et al. (2004) replicated the vowel length effect on lexical decision times in the presence of a concurrent articulatory suppression task, indicating that phonetic information affects word processing even when inner speech is unlikely to occur. These results suggest that phonological representations during reading form no unitary entity. Instead, phonological processing used for articulation purposes seems to be different from phonological representations used for lexical access. Additionally, Lukatela et al. also reported a weaker vowel length effect in a word naming task. Since word naming is usually supposed to involve post-lexical processes, this was interpreted as further evidence for the assumption that the vowel length effect is likely originating at a lexical and not a post-lexical level. Taken together, these studies convincingly demonstrated a vowel length effect during the processing of isolated words. However, Abramson and Goldinger (1997) explicitly state that "[i]t remains to be seen if these inner-speech effects will generalize to more natural reading tasks" (p. 1066). The overall goal of the present study is to fill this gap by examining the vowel length effect during normal sentence reading.

Comparatively few studies have assessed the role of phonological or phonetic information in lexical processing during natural sentence reading. Sentence reading studies typically rely on the assumption that lexical pro- cessing is reflected in specific eye movement parameters (see Rayner, 1998). For example, Pollatsek, Lesch, Morris, and Rayner (1992) used a gaze-contingent display change technique which allowed them to change the identity of a word during the initial saccade into the word, so that word information (the preview) before fixation of the word is not the same as the information when the eyes finally fixate the word. They reported that homophone previews facilitated reading relative to orthographically similar control previews, suggesting that phonological information is processed quite early, even before the eyes fixate on a word ("parafoveal processing", see also Liu, Inhoff, Ye, \& Wu, 2002; Miellet \& Sparrow, 2004; Pollatsek, Tan, \& Rayner, 2000).

A recent study by Ashby, Treiman, Kessler, and Rayner (2006) examined whether readers use parafoveal input to integrate vowel information into phonological representations. Subjects read sentences in which parafoveal previews either contained vowel phonemes that were concordant or discordant with the vowel phoneme in the target word. They observed shorter reading times for targets that were preceded by concordant previews, indicating that vowel phonemes are included already in early phonological representations during silent reading. However, this study does not provide an answer to the question of when and to what extent phonetic information, including vowel length information, might play a role in sentence reading.

While the sentence reading studies described above are still in line with the assumption of rather abstract phonological representations during lexical processing, a study that explicitly examined the influence of phonetic features (i.e., prosodic information) on lexical processing in sentence reading was conducted by Ashby and Clifton (2005). As a major result, words with two stressed syllables were fixated longer compared to words with only one stressed syllable, irrespective of word length. This finding was interpreted as being in line with the implicit prosody hypothesis (Fodor, 1998), which states that even during silent reading readers impose a prosodic contour on text. In line with the notion of an inner speech, readers seem to endogenously generate prosody information during silent reading. Since first fixation durations on the target words remained unaffected by the stress manipulation, the data suggested that stress assignment takes place during the completion of lexical access (see also Frost, 1998). However, it remained an open question whether 
this effect of prosody on temporal eye movement parameters was due to the specific pitch pattern or rather due to differences in pronunciation duration. Taken together, there is only sparse evidence for a phonetically informed phonology in natural sentence reading, and none of the previous studies addressed the question of whether vowel length information affects lexical processing during sentence processing.

\section{The Present Study}

The present study addresses the issue whether and when phonetic information is processed during lexical access in natural sentence reading. To this end, vowel length within target words was systematically manipulated, and target words were embedded in sentences. Lexical processing was assessed by analyzing fixation durations during sentence processing. If vowel length is processed lexically (Lukatela et al., 2004) and lexical access drives oculomotor control in reading (e.g., Reichle, Rayner, \& Pollatsek, 2003), then vowel length should affect eye movements in reading. In Experiment 1, participants read silently for comprehension. The aim was to replicate the vowel length effect (Abramson \& Goldinger, 1997; Lukatela et al., 2004) in natural sentence reading. In addition to the vowel length manipulation, word frequency was varied. Word frequency is known to influence the duration of lexical access, a phenomenon that is also reflected in fixation durations during reading (e.g., Rayner \& Duffy, 1986). If both vowel length and word frequency affect the same word processing stage during lexical access, one would expect stronger vowel length effects for low-frequency words (see Abramson \& Goldinger, 1997). Additionally, a thorough analysis of early vs. late temporal eye movement parameters should allow to infer the timeline of phonetic processing.

Experiment 2 involved oral instead of silent reading. Oral reading in some ways resembles the word naming task implemented by Lukatela et al. (2004), since both tasks involve the pronunciation of visually presented words. Lukatela et al. interpreted the marginal vowel length effect in word naming as evidence against a postlexical influence of vowel length information during word processing (see above). In line with this research, one might thus expect a smaller vowel length effect in oral as compared to silent reading, since oral reading (like naming) may place more weight on post-lexical processing (i.e., pronunciation).
In Experiment 3, a dual-task setting was implemented by adding a concurrent articulatory suppression task to the sentence reading task. Similar to the respective condition by Lukatela et al. (2004), this experiment allows to test whether the potential vowel length effect in sentence reading remains intact under circumstances which make the occurrence of inner speech unlikely. Experiment 3 can also be regarded as a control condition to Experiment 2, since both involve articulation, but only in Experiment 2 articulation is linked to the ongoing word processing task (see General Discussion for further details).

Experiment 4 also consisted of a dual-task setting in which silent reading was combined with a foot tapping task. It serves as a control condition for Experiments 2 and 3. If the articulation demands in these previous experiments attenuate the vowel length effect, one might attribute this finding to an overall unspecific increase in cognitive processing demands resulting from the additional (vocal) task. If this unspecific explanation is true, one would expect a similar attenuation of the vowel length effect during any secondary task, including foot tapping.

\section{Experiment 1}

In Experiment 1, target words with short vs. long vowels and of high vs. low lexical frequency were embedded in a controlled sentence environment. The targets were comparable in word length and the number of syllables. The main dependent measures referred to temporal parameters (fixation times) on the target word as indicators of lexical processing. If phonetic information is processed during lexical access, target words with short vowels should be read faster than target words with long vowels.

\section{Method}

Participants. Sixteen students from RWTH Aachen University with normal or corrected-to-normal vision took part in this experiment, eight female and eight male. Mean age was 26 years $(S D=8.20)$. All participants were naive about the purpose of the experiment. They gave their informed consent and received credits for participation.

Apparatus and Stimuli. Participants were seated 67 $\mathrm{cm}$ in front of a 21 ', cathode ray monitor (temporal reso- 
lution: $100 \mathrm{~Hz}$, spatial resolution: $1240 \times 1068$ pixels) with a keyboard in front of them. The spacebar of the keyboard was used during calibration routines. Eye movements were registered using a head-mounted Eyelink II infrared reflection system (SR Research, Canada). An eye camera measured the position of the pupil of the right eye with a temporal resolution of $500 \mathrm{~Hz}$ and a spatial resolution of $<0.022^{\circ}$ (equivalent to smaller than one character). A chin rest was used to minimize head movements.

Target words were systematically selected according to a $2 \times 2$ design with the factors vowel length (short vs. long) and word frequency (low vs. high). Vowel length was determined by referring to pronunciation rules in German. A vowel is pronounced long when it is doubled, e.g. in "Haar" (hair), or when it is followed by a "h", as in "Bahn" (train). Vowels are pronounced short when the following consonants are doubled, as in "Bett" (bed), or represent a of "ck", as in "Sack" (sack). Target words were either mono- or bisyllabic. For bisyllabic words, the vowel length manipulation always referred to the first syllable, whereas the second syllable was always unstressed and consisted of either an "e" or "er", which in German do not differ with respect to pronunciation duration.

All target words were embedded in the middle of single-line sentences (using fixed pitch Courier font), ranging in length from 70 to 80 character spaces. Each character subtends a third degree of visual angle. Since it is not possible to find German word pairs that solely dif- fer in vowel length, all target words and their surroundings were controlled with respect to a number of variables, and a comparatively large item pool of ninety-six words was generated. All target items were controlled for length, number of syllables, lexical frequency, orthographic regularity (position dependant bigram frequency), and word position on line (see Table 1). The pre-target word (N-1) was always an adjective that was controlled with respect to frequency and length. The post-target word $(\mathrm{N}+1)$ was always a length-controlled short conjunction or preposition of high lexical frequency (e.g., "and", "with", etc.). The word following the posttarget word $(\mathrm{N}+2)$ was controlled with respect to its length. Word frequency measures were taken from the CELEX database (Baayen, Piepenbrock, \& Gulikers, 1995), which was also the basis for the computation of the position-dependant bigram frequencies. A $2 \times 2$ ANOVA with the factors vowel length (short vs. long) and word frequency (low vs. high) revealed that none of the control variables referred to above were significantly affected by vowel length or word frequency, all $p>.10$, with the exception of a significant frequency difference between high and low frequency words, $F(1,92)=6.65, p=.012$. It should be noted that due to the rather strong constraints for selecting the target words the present frequency variation is not as large as in previous studies which specifically focussed on word frequency effects (e.g., Rayner \& Duffy, 1986).

Table 1

Characteristics of target words.

\begin{tabular}{lcccc} 
& \multicolumn{2}{c}{ High frequency } & \multicolumn{2}{c}{ Low frequency } \\
\cline { 2 - 5 } & Short vowel & Long vowel & Short vowel & Long vowel \\
\hline Word frequency (per million) & 66.00 & 67.13 & 2.46 & 2.33 \\
Number of letters & 4.54 & 4.54 & 4.58 & 4.46 \\
Number of syllables & 1.29 & 1.38 & 1.50 & 1.33 \\
Orthographic regularity (position-dependent & 2128 & 2119 & 2076 & 2066 \\
bigram frequency) & 32 & 34 & 34 & 35 \\
Word position on line (in letter units) & 426 & 505 & 277 & 272 \\
Pre-target word frequency (per million) & 5.96 & 5.58 & 5.92 & 5.88 \\
Pre-target word length & 3.00 & 2.96 & 3.00 & 3.04 \\
Post-target word length & & & & \\
\hline
\end{tabular}


Procedure. At the beginning of the experiment, the eye-tracking system was calibrated using a three-point horizontal calibration routine. Calibration was repeated at the beginning of each trial. After each calibration, participants pressed the space bar and the sentence appeared on the screen. Subjects were instructed to read the sentence silently for comprehension, and afterwards pressed the space bar again to start the next calibration. At unpredictable intervals, the sentences were followed by a comprehension question (12 in total). Participants were instructed to answer orally as precisely as possible. Two measures were computed on the basis of the answers. First, the number of answers that did not contain any relevant items from the previously read sentence were counted as errors (error rate). This measure was used as an index for superficial text comprehension. Furthermore, all correct answers contained more than one content word, e.g. "the coloured flag". Subjects were instructed to recall all relevant content words (maximum $=25$ ) as precisely as possible, so that the number of correctly recalled content words served as a more detailed measure of text comprehension.

Each participant completed 96 target sentences which were intermixed with filler sentences that were not further analysed. Prior to the experimental sentences, ten sentences and two questions were added to accommodate subjects to the experimental situation.

Design. The independent variables vowel length (short vs. long) and word frequency (low vs. high) were manipulated intraindividually. As temporal dependent variables, first fixation durations, gaze durations, and rereading time on the target words were measured. First fixation durations represent the duration of the first fixation on the target word. Gaze durations are defined as the sum of the durations of all fixations before the word is left for the first time and is affected by the speed of lexical access. Rereading time includes all fixations on the target after it was left for the first time and can be interpreted as an indicator of post-lexical processes (e.g., Rayner, 1998). Furthermore, the probability of skipping the target word and the initial landing position of the first saccade into the word were computed. Temporal parameters and skipping were also computed for the pre-target word $(\mathrm{N}-1)$ and the post-target words $(\mathrm{N}+1, \mathrm{~N}+2)$. Finally, sentence reading times, the relative frequency of regressions (saccades from right to left) and mean progressive saccade amplitudes were analysed across experiments to assess overall processing difficulty. For the target-word analyses, subject-based $\left(F_{1}\right)$ and item-based $\left(F_{2}\right) 2 \times 2$ ANOVAs were conducted. Due to the overall greater $p$-values in the item-based analyses for all dependent variables, $F_{2}$ will only be reported to complement significant $F_{1}$-ratios to increase readability.

\section{Results}

All participants answered at least ten out of twelve comprehension questions correctly. The mean error rate amounted to 0.50 errors $(S D=0.63)$. The mean number of recalled content words amounted to $20.56(S D=2.13)$. Because of blinks or measurement error, approximately $5 \%$ of the trials were discarded. The mean sentence reading time amounted to $12,356 \mathrm{~ms}(S D=2,489)$.

\section{Table 2}

Mean first fixation durations, gaze durations, and rereading time in Experiment 1, a) on target words with short vs. long vowels and of high vs. low frequency, b) on surrounding words as a function of target word vowel length.

\begin{tabular}{cccccccc}
\hline a) & \multicolumn{1}{l}{ Vowel length } & Frequency & \multicolumn{2}{l}{ First fixation duration } & \multicolumn{2}{c}{ Gaze duration } & \multicolumn{2}{c}{ Rereading time } \\
\hline \multirow{3}{*}{ short } & high & 201 & 8.55 & 224 & 11.13 & 136 & 26 \\
& low & 230 & 8.94 & 259 & 19.96 & 148 & 20 \\
\multirow{4}{*}{ long } & high & 215 & 11.68 & 252 & 17.91 & 112 & 25 \\
& low & 226 & 9.65 & 262 & 17.26 & 157 & 26 \\
\hline
\end{tabular}




\begin{tabular}{|c|c|c|c|c|c|c|c|}
\hline \multirow[t]{2}{*}{ Word } & \multirow[t]{2}{*}{ Vowel length } & \multicolumn{2}{|c|}{ First fixation duration } & \multicolumn{2}{|c|}{ Gaze duration } & \multicolumn{2}{|c|}{ Rereading time } \\
\hline & & $M$ & $S E$ & $M$ & $S E$ & $M$ & $S E$ \\
\hline \multirow[t]{2}{*}{$\mathrm{N}-1$} & short & 223 & 10 & 260 & 16 & 239 & 46 \\
\hline & long & 244 & 25 & 292 & 35 & 215 & 43 \\
\hline \multirow[t]{2}{*}{$\mathrm{N}+1$} & short & 230 & 25 & 251 & 31 & 79 & 14 \\
\hline & long & 255 & 30 & 272 & 36 & 90 & 13 \\
\hline \multirow[t]{2}{*}{$\mathrm{N}+2$} & short & 233 & 23 & 278 & 31 & 156 & 26 \\
\hline & long & 231 & 13 & 279 & 19 & 157 & 20 \\
\hline
\end{tabular}

Table 2a presents oculomotor parameters on the target words. The $2 \times 2$ ANOVA yielded no significant main effect of vowel length on first fixation durations, $F_{1}<1$, whereas the main effect of word frequency was significant, $F_{l}(1,15)=27.46, p<.001, \eta_{p}{ }^{2}=.647, F_{2}(1,92)=$ $8.40, p=.005, \eta_{p}{ }^{2}=.090$, indicating longer first fixation durations on low (vs. high) frequency words. There was no significant interaction of vowel length and word frequency, $F_{l}(1,15)=3.16, p=.096$.

Most importantly, vowel length significantly affected gaze duration, $F_{1}(1,15)=5.51, p=.033, \eta_{p}{ }^{2}=.270, F_{2}$ $(1,92)=5.41, p=.022, \eta_{p}{ }^{2}=.059$, indicating longer gaze durations for words that contained a long vowel compared to words that contained a short vowel. The main effect of word frequency (high vs. low) on gaze durations was only significant in the subject-based analysis, $F_{l}$ $(1,15)=5.91, p=.028, \eta_{p}{ }^{2}=.283, F_{2}(1,92)=1.61, p=$ .208. There was no significant interaction between vowel length and word frequency, $F_{l}(1,15)=1.91, p=.187$.

There was no significant main effect of vowel length on rereading time, $F_{1}<1$, but a significant main effect of word frequency in the subject-based analysis, $F_{1}(1,15)=$ $8.19, p=.012, \eta_{p}{ }^{2}=.353$, but not in the item-based analysis, $F_{2}(1,92)=2.01, p=.160$. There was no significant interaction of vowel length and frequency, $F_{1}(1,15)$ $=2.29, p=.151$.

The mean initial landing position on the target words was located at $2.75(S E=0.09)$ letter units, and was not affected by the experimental manipulations (all $F<1$ ).
The mean overall skipping probability for the target words amounted to $19.46 \%(S E=2.21)$ and was not affected by the experimental manipulations (all $F<1$ ).

Further analyses (dependant samples $t$-tests) were conducted to determine whether the crucial vowel length manipulation affected skipping and/or temporal parameters on the words surrounding the target. The skipping probabilities for words $\mathrm{N}-1, \mathrm{~N}+1$, and $\mathrm{N}+2$ amounted to $6.1 \%(S E=1.9), 41.3 \%(S E=4.2)$, and $15.4 \%(S E=2.1)$, respectively, but they were not significantly affected by the crucial vowel length manipulation, all $p>.10$. Initial fixation durations, gaze durations, and rereading times on words $\mathrm{N}-1, \mathrm{~N}+1$, and $\mathrm{N}+2$ were not significantly affected by the vowel length of the target word, all $p>.10$, except for a significant increase of initial fixation durations on $\mathrm{N}+1$ (255 ms vs. $230 \mathrm{~ms}$ ) following target words with long vowels, $t(15)=2.21, p=.043$ (see Table $2 b$ ).

\section{Discussion}

The most important finding of Experiment 1 is the presence of a vowel length effect on gaze durations. Gaze durations are traditionally assumed to be largely influenced by lexical access (e.g., Reichle et al., 1993). Therefore, it seems reasonable to conclude that phonetic information plays a significant role during lexical access in silent sentence reading.

Interestingly, and in contrast to the observed word frequency effect, the vowel length effect was not significantly present in first fixation durations, suggesting that vowel length information is likely processed at later 
stages of word processing. Further evidence for a rather late effect of vowel length information is provided by the observed increase of initial fixation durations on the posttarget word. This difference in the processing timeline between word frequency and vowel length is further corroborated by the absence of an interaction between both independent variables. In lexical decision studies, a stronger vowel length effect on low frequency words was reported (Abramson \& Goldinger, 1997), and early prelexical effects (e.g., phonological effects) are often limited to low frequency words (see Jared \& Seidenberg, 1990; Lee, Binder, Kim, Pollatsek, \& Rayner, 1999). Thus, the absence of a corresponding interaction in the present experiment suggests that in normal sentence reading vowel length affects lexical processing rather late during lexical processing, presumably around the time of the completion of lexical access. Additional evidence against early processing of vowel length information comes from the analysis of reading times on the pretarget word and from the skipping rates of the target words. Neither of these parameters was affected by the vowel length of the target, indicating that phonetic properties of a word play no substantial role prior to fixation.

Since rereading times as well as gaze durations on words $\mathrm{N}+1$ and $\mathrm{N}+2$ remained unaffected by the vowel length manipulation, it seems as if post-lexical processing of vowel length does either not occur in silent reading, or is at least not reflected in the eye movement record. However, post-lexical processing of phonetic information is a necessary precondition of oral reading, where the production of phonetic codes is an integrative part of the reading task. Experiment 2 will clarify to what extent oral reading will modulate the influence of vowel length on oculomotor control.

\section{Experiment 2}

Experiment 2 was designed in the same way as Experiment 1 , with the exception that participants were asked to read the sentences orally. One the one hand, one might expect that oral reading emphasizes the need for phonetic representations, which are a prerequisite for articulation. As a result, one might expect a greater vowel length effect as compared to silent reading. On the other hand, the build-up of phonetically informed phonological representations for lexical access might be distinct from codes used for articulation purposes. Based on this reasoning, one might assume that oral reading demands rather place more weight on post-lexical processing (i.e., pronunciation), so that effects related to lexical access might be attenuated.

\section{Method}

Participants. Sixteen new students from RWTH Aachen university with normal or corrected-to-normal vision took part in this experiment, eight female and eight male. Mean age was 29 years $(\mathrm{SD}=8.52)$. They gave their informed consent and received credits for participation.

Apparatus, Stimuli, Procedure \& Design. The apparatus, stimuli, and design were the same as in Experiment 1. The procedure was also the same, but participants were asked to read orally instead of silently.

\section{Results}

All participants answered at least nine out of twelve comprehension questions correctly. The mean error rate amounted to 0.44 errors $(S D=0.89)$. The mean number of recalled content words amounted to $21.38(S D=2.85)$. The mean sentence reading time amounted to $13,321 \mathrm{~ms}$ $(S D=2,698)$. 
Table 3

Mean first fixation durations, gaze durations, and rereading time in Experiment 2, a) on target words with short vs. long vowels and of high vs. low frequency, b) on surrounding words as a function of target word vowel length.

\begin{tabular}{cccccccc}
\hline a) & \multicolumn{1}{l}{ Vowel length } & Frequency & \multicolumn{2}{l}{ First fixation duration } & \multicolumn{2}{c}{ Gaze duration } & \multicolumn{2}{c}{ Rereading time } \\
\hline \multirow{3}{*}{ short } & & $M$ & $S E$ & $M$ & $S E$ & $M$ & $S E$ \\
& high & 204 & 12.81 & 239 & 14.21 & 115 & 20 \\
\multirow{4}{*}{ long } & low & 219 & 14.26 & 253 & 13.15 & 120 & 16 \\
& high & 214 & 15.02 & 245 & 16.29 & 130 & 18 \\
& low & 215 & 11.23 & 250 & 13.41 & 155 & 22 \\
\hline
\end{tabular}

\begin{tabular}{|c|c|c|c|c|c|c|c|}
\hline \multirow[t]{2}{*}{ Word } & \multirow[t]{2}{*}{ Vowel length } & \multicolumn{2}{|c|}{ First fixation duration } & \multicolumn{2}{|c|}{ Gaze duration } & \multicolumn{2}{|c|}{ Rereading time } \\
\hline & & $M$ & $S E$ & $M$ & $S E$ & $M$ & $S E$ \\
\hline \multirow[t]{2}{*}{ N-1 } & short & 239 & 17 & 291 & 15 & 170 & 19 \\
\hline & long & 230 & 16 & 284 & 15 & 180 & 24 \\
\hline \multirow[t]{2}{*}{$\mathrm{N}+1$} & short & 221 & 15 & 244 & 17 & 81 & 12 \\
\hline & long & 229 & 19 & 261 & 26 & 100 & 15 \\
\hline \multirow[t]{2}{*}{$\mathrm{N}+2$} & short & 226 & 14 & 272 & 13 & 146 & 18 \\
\hline & long & 229 & 15 & 289 & 14 & 144 & 19 \\
\hline
\end{tabular}

Table 3 a presents oculomotor parameters on the target words. The ANOVA yielded no significant main effect of vowel length on first fixation durations, $F_{1}<1$. There was also no significant main effect of word frequency, $F_{l}(1,15)=2.05, p=.127$, although in both vowel length conditions first fixation durations were nominally prolonged for low compared to high frequency words. There was no significant interaction between vowel length and word frequency, $F_{l}(1,15)=1.47, p=.244$.

Unlike in Experiment 1, neither vowel length nor word frequency significantly affected gaze durations, both $F_{1}<1.3$. However, in both vowel length conditions gaze durations were nominally prolonged for low compared to high frequency words (see Table 3a). There was no significant interaction between vowel length and word frequency, $F_{1}<1$. There were also no significant main effects or interaction on rereading time, all $p>.10$.
The mean initial landing position on the target words was located at $2.65(S E=0.08)$ letter units, and was not significantly affected by the experimental conditions (all $F<1$ ). The mean overall skipping probability for the target words amounted to $17.79 \%(S D=9.05)$, but was neither significantly affected by vowel length nor word frequency, $F_{I}(1,15)=2.90, p=.110$ and $F_{l}(1,15)=3.72$, $p=.073$, respectively. There was no significant interaction of vowel length and word frequency, $F_{l}(1,15)=$ $1.62, p=.223$.

Further analyses (dependant samples $t$-tests) were conducted to determine whether the crucial vowel length manipulation affected skipping and/or temporal parameters on the words surrounding the target word. The skipping probabilities for words $\mathrm{N}-1, \mathrm{~N}+1$, and $\mathrm{N}+2$ amounted to $6.2 \%(S E=1.8), 36.1 \%(S E=4.4)$, and $13.0 \%(S E=2.2)$, respectively, but they were not significantly affected by the crucial vowel length manipulation, all $p>.10$. Initial fixation durations, gaze durations, and 
rereading times on words $\mathrm{N}-1, \mathrm{~N}+1$, and $\mathrm{N}+2$ were not significantly affected by the vowel length of the target word, all $p>.10$, except for a significant increase of rereading times on $\mathrm{N}+1$ following target words with long vowels $(100 \mathrm{~ms}$ vs. $81 \mathrm{~ms}), t(15)=2.40, p=.030$ (see Table $3 \mathrm{~b}$ for an overview of temporal parameters). However, it should be noted that rereading of $\mathrm{N}+1$ occurred only sparsely, so that the corresponding temporal measures are likely not reliable.

\section{Discussion}

Experiment 2 was designed to decide whether the vowel length effect found in silent reading is also present in oral reading. As a result, there was no indication of a vowel length effect in oral reading, since none of the reported parameters were significantly affected by vowel length. A closer look at the data in Table 3 a reveals that this finding is unlikely driven by a lack of statistical power, since there was not even a noteworthy tendency for a difference in gaze durations between short- and long-vowel words.

This observation is clearly not compatible with the claim that oral reading emphasizes the encoding of phonetic information during lexical access. Thus, it is rather likely that phonetic processing during lexical access is a distinct process from the assembly of a phonetic representation necessary for articulation purposes. Probably, oral reading demands place more weight on post-lexical processing (i.e., pronunciation) as compared to silent reading, so that phonetic effects related to lexical access are severely attenuated and no longer show up in gaze durations. This interpretation is in line with previous single word reading studies which reported that that the vowel length effect is attenuated in word naming tasks as compared to lexical decision tasks (Lukatela et al., 2004).

In contrast to Experiment 1, first fixation durations and gaze durations were not significantly affected by word frequency, even though the distribution of means was in accordance with a classic frequency effect. Probably, oral reading posed additional demands on processing so that word frequency effects were slightly attenuated. Additionally, it should be noted that due to the rather strong constraints for selecting target words the present frequency variation is not as large as in previous studies which specifically focussed on word frequency effects (e.g., Rayner \& Duffy, 1986).

\section{Experiment 3}

In their series of lexical decision experiments, Lukatela et al. (2004) demonstrated that the effects of vowel length on lexical decision times were still present in an articulatory suppression condition. Assuming that articulatory suppression should make the occurrence of inner speech unlikely, this finding suggests that the vowel length effect is not based on inner speech processes. However, lexical decision differs considerably from normal reading. Thus, the present experiment aims at clarifying whether the vowel length effect might be based on inner speech processes in normal sentence reading.

\section{Method}

Participants. Sixteen new students from RWTH Aachen university with normal or corrected-to-normal vision took part in this experiment, twelve female and four male. Mean age was 27 years $(S D=7.89)$. They gave their informed consent and received credits for participation.

Apparatus, Stimuli, Procedure \& Design. The apparatus, stimuli, and design were the same as in Experiment 1. The procedure was also the same with the exception that the participants were instructed to orally repeat the syllable "tau" according to the rhythm of a metronome (2 syllables per second) throughout the experiment except for the time intervals that were reserved for answering the comprehension questions. The experimenter carefully ensured that the participants followed the instructions.

\section{Results}

All participants answered at least nine out of twelve comprehension questions correctly. The mean error rate amounted to 0.94 errors $(S D=1.06)$. The mean number of recalled content words amounted to $18.00(S D=3.29)$. The mean sentence reading time amounted to $12,299 \mathrm{~ms}$ $(S D=2165)$.

Table 4a presents oculomotor parameters on the target words. The ANOVA yielded no significant main effect of vowel length (short vs. long) on first fixation durations, $F_{1}<1$. However, there was a significant main effect of word frequency, $F_{I}(1,15)=26.42, p<.001, \eta_{p}{ }^{2}=.638$, $F_{2}(1,92)=9.82, p=.002, \eta_{p}{ }^{2}=.096$, but no significant interaction between vowel length and word frequency, $F_{l}$ $<1$. 


\section{Table 4}

Mean first fixation durations, gaze durations, and rereading time in Experiment 3, a) on target words with short vs. long vowels and of high vs. low frequency, b) on surrounding words as a function of target word vowel length.

\begin{tabular}{cccccccc}
\hline a) & \multicolumn{1}{l}{ Vowel length } & Frequency & \multicolumn{2}{l}{ First fixation duration } & \multicolumn{2}{c}{ Gaze duration } & \multicolumn{2}{c}{ Rereading time } \\
\hline \multirow{3}{*}{ short } & & $M$ & $S E$ & $M$ & $S E$ & $M$ & $S E$ \\
& high & 202 & 7.96 & 230 & 12.07 & 126 & 16 \\
\multirow{4}{*}{ long } & low & 219 & 7.66 & 251 & 11.20 & 105 & 26 \\
& high & 198 & 7.29 & 228 & 13.05 & 100 & 17 \\
& low & 214 & 8.31 & 245 & 16.32 & 116 & 26 \\
\hline
\end{tabular}

\begin{tabular}{|c|c|c|c|c|c|c|c|}
\hline \multirow[t]{2}{*}{ Word } & \multirow[t]{2}{*}{ Vowel length } & \multicolumn{2}{|c|}{ First fixation duration } & \multicolumn{2}{|c|}{ Gaze duration } & \multicolumn{2}{|c|}{ Rereading time } \\
\hline & & $M$ & $S E$ & $M$ & $S E$ & $M$ & $S E$ \\
\hline \multirow[t]{2}{*}{$\mathrm{N}-1$} & short & 227 & 12 & 280 & 19 & 187 & 43 \\
\hline & long & 221 & 12 & 270 & 20 & 175 & 31 \\
\hline \multirow[t]{2}{*}{$\mathrm{N}+1$} & short & 206 & 14 & 220 & 17 & 64 & 14 \\
\hline & long & 208 & 11 & 226 & 12 & 55 & 16 \\
\hline \multirow[t]{2}{*}{$\mathrm{N}+2$} & short & 216 & 10 & 243 & 15 & 126 & 23 \\
\hline & long & 223 & 8 & 262 & 12 & 117 & 21 \\
\hline
\end{tabular}

Gaze durations were not significantly affected by vowel length, $F_{1}<1$, but by word frequency, $F_{l}(1,15)=$ $6.26, \mathrm{p}=.024, \eta_{p}{ }^{2}=.295, F_{2}(1,92)=4.37, p=.039, \eta_{p}{ }^{2}=$ .045 . There was no significant interaction between vowel length and word frequency, $F_{1}<1$. There were no significant main effects and no significant interaction with respect to rereading times, all $p>.10$.

The mean initial landing position on the target words was located at $2.68(S E=0.07)$ letter units, and was not affected by the experimental manipulations (all $F<1$ ). The mean overall skipping probability for the target words amounted to $21.26 \%(S D=12.43)$ and was neither significantly affected by vowel length nor word frequency, $F_{l}<1$ and $F_{l}(1,15)=3.34, p=.088$, respectively. There was no significant interaction of vowel length and word frequency, $F_{l}<1$.
Further analyses (dependant samples $t$-tests) were conducted to determine whether the crucial vowel length manipulation affected skipping and/or temporal parameters on the words surrounding the target. The skipping probabilities for words $\mathrm{N}-1, \mathrm{~N}+1$, and $\mathrm{N}+2$ amounted to $8.0 \%(\mathrm{SE}=2.5), 51.9 \%(\mathrm{SE}=4.6)$, and $18.2 \%(\mathrm{SE}=$ $2.5)$, respectively, but they were not significantly affected by the crucial vowel length manipulation, all $p>.10$. Initial fixation durations, gaze durations, and rereading times on words $\mathrm{N}-1, \mathrm{~N}+1$, and $\mathrm{N}+2$ were not significantly affected by the vowel length of the target word, all $p>$ .10 (see Table 4b).

\section{Discussion}

This experiment was designed to test whether the vowel length effect persists under an articulatory suppression condition in sentence reading. The data suggest that this is not the case. As in Experiment 2, there was not 
even a trend towards a vowel length effect (see Table 4a), making an explanation in terms of a lack of statistical power unlikely. This result shows that the vowel length effect that was demonstrated under articulatory suppression demands in lexical decision tasks (Lukatela et al., 2004) does not generalise to normal reading. As in Experiment 2 , the phonetic representations that were necessary for speech production might have attenuated the effects of phonetic representations used during lexical access. Probably, the vowel length effect in normal reading is indeed closely related to inner speech processes, and any additional demands that prevent the occurrence of inner speech (like oral reading in Experiment 2 and articulatory suppression in Experiment 3 ) in turn disrupt the processing of vowel length information during lexical access.

According to Baddeley, Lewis, and Vallar (1984), articulatory suppression tasks occupy phonological working memory, subsequently suppressing further phonological processing. Many researchers agree that phonological codes remain active after lexical access to store words in memory for sentence comprehension (Baddeley, Thomson, \& Buchanan, 1975; McCutchen \& Perfetti, 1982; Meyer, Shvaneveldt, \& Ruddy, 1974; Perfetti, Zhang, \& Berent, 1992). However, despite the overall disruption of phonological working memory, the low error rates indicate that participants in the present experiment were still able to read for comprehension (see also Slowiaszek \& Clifton, 1980; Waters, Komoda, \& Arbuckle, 1985).

\section{Experiment 4}

Experiment 4 was mainly conducted as a control condition for Experiments 2 and 3. These experiments differ from Experiment 1 not only with respect to the specific articulation demands, but also with respect to the mere presence of a secondary task. Thus, one might argue that any secondary task might disrupt the vowel length effect due to an unspecific increase of cognitive load. If the latter assumption is true, one would expect that the vowel length effect is also eliminated when a secondary task is not related to articulation. Thus, an additional foot tapping task was introduced in Experiment 4.

\section{Method}

Participants. Sixteen new students from RWTH Aachen university with normal or corrected-to-normal vision took part in this experiment, nine female and seven male. Mean age was 24 years $(S D=2.36)$. They gave their informed consent and received credits for participation.

Apparatus, Stimuli, Procedure \& Design. The apparatus, stimuli, and design were the same as in the previous experiments. The procedure was also the same with the exception that participants were instructed to use their right foot to tap along the lines of a square that was painted on the floor. They received some training prior to testing to assure that they are able to execute the task without looking at the floor. Participants were asked to move their foot in accordance with the rhythm provided by a metronome ( 2 taps per second) throughout the experiment. The experimenter carefully ensured that the participants followed these instructions.

\section{Results}

All participants answered at least nine out of twelve comprehension questions correctly. The mean error rate amounted to 0.63 errors $(S D=0.81)$. The mean number of recalled content words amounted to $19.75(S D=2.54)$. The mean sentence reading time amounted to $12,565 \mathrm{~ms}$ $(S D=2,901)$.

Table 5a presents oculomotor parameters on the target words. There was no significant main effect of vowel length on first fixation durations, $F_{l}(1,15)=1.86, p=$ .193. The main effect of word frequency was only marginally significant in the subject-based analysis, $F_{I}(1,15)$ $=3.88, p=.068, \eta_{p}{ }^{2}=.230$, indicating longer first fixation durations on low frequency words compared to high frequency words, but not significant in the item-based analysis, $F_{2}(1,92)=2.12, p=.149$. No significant interaction effect was found between vowel length and word frequency, $F_{l}<1$. 


\section{Table 5}

Mean first fixation durations, gaze durations, and rereading time in Experiment 4, a) on target words with short vs. long vowels and of high vs. low frequency, b) on surrounding words as a function of target word vowel length.

\begin{tabular}{cccccccc}
\hline a) & \multicolumn{1}{l}{ Vowel length } & Frequency & \multicolumn{2}{l}{ First fixation duration } & \multicolumn{2}{c}{ Gaze duration } & \multicolumn{2}{c}{ Rereading time } \\
\hline \multirow{3}{*}{ short } & high & 178 & 8.38 & 197 & 10.02 & 130 & 26 \\
& low & 194 & 8.60 & 249 & 19.91 & 122 & 20 \\
\multirow{4}{*}{ long } & high & 191 & 9.38 & 235 & 10.15 & 140 & 24 \\
& low & 198 & 11.22 & 244 & 17.16 & 167 & 27 \\
\hline
\end{tabular}

\begin{tabular}{|c|c|c|c|c|c|c|c|}
\hline \multirow[t]{2}{*}{ Word } & \multirow[t]{2}{*}{ Vowel length } & \multicolumn{2}{|c|}{ First fixation duration } & \multicolumn{2}{|c|}{ Gaze duration } & \multicolumn{2}{|c|}{ Rereading time } \\
\hline & & $M$ & $S E$ & $M$ & $S E$ & $M$ & $S E$ \\
\hline \multirow[t]{2}{*}{$\mathrm{N}-1$} & short & 225 & 17 & 284 & 19 & 208 & 45 \\
\hline & long & 225 & 12 & 278 & 13 & 228 & 46 \\
\hline \multirow[t]{2}{*}{$\mathrm{N}+1$} & short & 222 & 14 & 254 & 21 & 98 & 21 \\
\hline & long & 216 & 10 & 244 & 15 & 117 & 21 \\
\hline \multirow[t]{2}{*}{$\mathrm{N}+2$} & short & 202 & 10 & 232 & 10 & 168 & 31 \\
\hline & long & 209 & 10 & 253 & 11 & 186 & 30 \\
\hline
\end{tabular}

As in Experiment 1, vowel length significantly affected gaze durations, $F_{l}(1,15)=6.31, p=.024, \eta_{p}{ }^{2}=$ $.296, F_{2}(1,92)=3.95, p=.049, \eta_{p}{ }^{2}=.042$, indicating longer gaze durations for words that contained a long vowel compared to words that contained a short vowel. The main effect of word frequency on gaze durations was marginally significant in the subject-based analysis, $F_{I}(1,15)=4.13, p=.060$, and significant in the itembased analysis, $F_{2}(1,92)=10.78, p=.001, \eta_{p}{ }^{2}=.108$. There was a marginally significant interaction between vowel length and word frequency in the subject-based analysis, $F_{l}(1,15)=4.43, p=.053, \eta_{p}{ }^{2}=.228$, but not in the item-based analysis, $F_{2}(1,92)=1.35, p=.249$.

Rereading times were not affected by vowel length, $F_{l}$ $<1$, but there was a marginally significant main effect of word frequency, $F_{l}(1,15)=3.81, p=.070, \eta_{p}{ }^{2}=.203$, $F_{2}(1,92)=2.75, p=.09, \eta_{p}{ }^{2}=.030$, indicating longer rereading times for low frequency words. There was no significant interaction, $F_{1}<1$.

The mean initial landing position on the target words was located at $2.79(S E=0.06)$ letter units, and was not affected by the experimental manipulations (all $F<1$ ). The mean overall skipping probability for the target words amounted to $25.43 \%(S D=14.88)$, and was neither significantly affected by vowel length, $F<1$, nor word frequency, $F_{l}(1,15)=2.91, p=.109$. However, there was a significant interaction of vowel length and word frequency, $F_{l}(1,15)=8.13, p=.012, \eta_{p}{ }^{2}=.352, F_{2}(1,92)=$ $4.00, p=.048, \eta_{p}{ }^{2}=.042$, indicating that low-frequency target words were skipped more often when they contained a short vowel $(M=25.7 \%, S E=5.2)$ compared to a long vowel $(M=20.8 \%, S E=3.3)$, whereas high frequency target words were skipped more often when they contained a long vowel $(M=31.2 \%, S E=4.2)$ compared to a short vowel $(M=24.0 \%, S E=3.8)$. 
Further analyses (dependant samples $t$-tests) were conducted to determine whether the crucial vowel length manipulation affected skipping and/or temporal parameters on the words surrounding the target. The skipping probabilities for words $\mathrm{N}-1, \mathrm{~N}+1$, and $\mathrm{N}+2$ amounted to $8.2 \%(S E=2.3), 39.4 \%(S E=4.9)$, and $19.3 \%(S E=2.1)$, respectively, but they were not significantly affected by the crucial vowel length manipulation, all $p>.10$. Initial fixation durations, gaze durations, and rereading times on words $\mathrm{N}-1, \mathrm{~N}+1$, and $\mathrm{N}+2$ were not significantly affected by the vowel length of the target word, all $p>.10$ (see Table 5b).

\section{Discussion}

The aim of Experiment 4 was to test whether the vowel length effect observed in Experiment 1 is suppressed under any type of cognitive load, or solely under additional task demands that involve articulation processes (Experiments 2 and 3). The results clearly support the latter option. Under foot tapping conditions, the data replicate the significant vowel length effect on gaze durations from the Experiment 1. The vowel length effect tended to be stronger for high frequency words compared to low frequency words (see Table 5a), but this interaction was neither clearly significant in the subject-based analysis nor in the item-based analysis and will thus not be further interpreted.

As in some of the previous experiments, the word frequency effect was rather weak, probably due to the lack of a strong word frequency variation. However, the data suggested a significant disordinal interaction between frequency and vowel length. A closer look revealed that target words with short vowels were skipped more often for low-frequency words, but this pattern was reversed for high-frequency targets. Since this rather inconsistent pattern was not present in Experiment 1, it may be attributed to random factors (note the overall large amount of dependent variables analyzed in this study) rather than to a meaningful mechanism during vowel length processing.

Unlike in Experiment 1, there was no systematic prolongation of initial fixation durations on the post-target word. In fact, none of the temporal parameters related to words surrounding the target word were affected by the vowel length manipulation, making it unlikely that vowel length information affects pre- and post-lexical stages of word processing relevant to oculomotor control.

\section{Cross-Experiment Comparisons}

As a final analysis, error rates, the number of recalled content words, sentence reading duration, progressive saccade amplitudes, regression rates and initial landing positions were compared across all four experiments. This was done to check whether there is any additional evidence for differences in overall processing difficulty between the experimental conditions that may provide further insight into explaining the different result patterns. The subject-based ANOVA indicated no significant differences across experiments regarding the number of errors in response to the comprehension questions (overall $M=0.60), F<1$, regarding the sentence reading duration (overall $M=12,636 \mathrm{~ms}$ ), $F<1$, the regression rate (overall $M=32 \%), F(3,60)=1.70, p=.177$, and the mean initial landing position on the target words (overall $M=$ 2.72 letter units), $F<1$.

However, the number of correctly recalled content words differed significantly across experiments, $F(3,60)$ $=4.45, p=.007$. Post hoc tests (Tukey) revealed that the mean in the articulatory suppression experiment (Experiment 3, $M=18$ ) significantly differed from the mean of both Experiment $1(M=20.56, p=.049)$ and Experiment $2(M=21.38, p=.005)$. The mean progressive saccade amplitude also differed significantly across experiments, $F(3,60)=4.55, p=.006$. Post hoc tests (Tukey) suggested that oral reading led to shorter saccade amplitudes $(M=$ 6.18 letter units) compared to both dual-task conditions in Experiment $3(M=7.88, p=.009)$ and $4(M=7.66, p=$ .034). The difference between Experiment $1(M=7.45)$ and 2 was only marginally significant $(p=.09)$.

Taken together, there was evidence for shorter saccade amplitudes in oral reading (in line with previous studies by Heller, 1982; Hendriks \& Kolk, 1997) and for lower text comprehension during articulatory suppression, whereas most of the global parameters remained remarkably unaffected by the different experimental conditions. 


\section{General Discussion}

The aim of the present study was to test whether and how phonetic properties of words inform the word identification process during sentence reading. To this end, vowel length within target words was varied and gaze durations were measured as an indicator of lexical access (Reichle et al., 2003). As a result, there was a significant vowel length effect on gaze durations in silent reading (Experiments 1 and 4), but no effect of vowel length on gaze durations when participants were involved in a secondary task involving articulation processes (Experiments 2 and 3). The vowel length effect in sentence reading is in line with earlier studies which reported a vowel length effect in lexical decision tasks (Abramson \& Goldinger, 1997; Lukatela et al., 2004).

\section{The Timeline of Vowel Length Processing}

The inclusion of word frequency as a second independent variable was useful to shed further light on the timeline of vowel length processing. Whereas in Experiment 1 and (marginally) in Experiment 4 word frequency already affected first fixation durations, the vowel length effect seemed to occur later during lexical processing. In Experiment 1, there was even an increase of first fixation durations on the post-target word after target words with long (vs. short) vowels. Furthermore, there was no stronger effect of vowel length on low frequency words, a pattern that is typical for early effects on lexical processing (see Jared \& Seidenberg, 1990; Lee, Binder, Kim, Pollatsek, \& Rayner, 1999). Final evidence against early processing of vowel length comes from the lack of any vowel length effects on the pre-target word and from the absence of a modulation of target word skipping rates, indicating that phonetic properties of a word play no substantial role prior to fixation. Taken together, these observations point to a rather late influence of phonetic information, probably around the time of the completion of lexical access. Thus, previous findings in which a strong interaction between vowel length and frequency was interpreted as a marker for early vowel length processing in lexical decision studies (Abramson \& Goldinger, 1997) do not seem to transfer to normal sentence reading.

Interestingly, rereading times as well as gaze durations on words $\mathrm{N}+1$ and $\mathrm{N}+2$ remained unaffected by the vowel length manipulation in Experiments 1 and 4. Therefore, it seems as if post-lexical processing of vowel length does either not occur in silent reading, or is at least not reflected in the eye movement record.

The assumption that phonetic information processing is part of lexical access is corroborated by results reported by Lukatela et al. (2004), who showed that long-vowel words benefit more from identity priming than shortvowel words. This implies that the activation rate for the representation of a short-vowel word is higher than for a long-vowel word, leading to faster lexical processing.

Note that the overall timeline observed in the present study resembles the influence of another phonetic property, lexical stress, on eye movements during reading (Ashby \& Clifton, 2005). Probably, the increase of pronunciation duration for both long vowels and stressed syllables affects lexical access in a comparable manner.

\section{Modulation of the Vowel Length Effect Across Ex- periments}

One of the main findings is the modulation of the vowel length effect across experiments. While it was present in silent reading (Experiments 1 and 4), there was no vowel length effect when participants were involved in a concurrent articulation task (Experiments 2 and 3). A reasonable interpretation of this result relates to the notion of inner speech during silent reading (Brown, 1958; Egger, 1904; Fodor, 1998; Huey, 1908/1968). In Experiment 2 , inner speech was replaced by overt speech due to the oral reading demand, and in Experiment 3 articulatory suppression likely suppressed the occurrence of inner speech. When the build-up of phonetic representations is assumed to be part of inner speech, one would not expect a vowel length effect in conditions where inner speech is prevented. Therefore, this explanation is in line with the observed modulation of the vowel length effect across experiments.

While only comparatively few research has been devoted to inner speech during silent reading, more effort has been invested into the study of overt speech during oral reading. Overt speech typically lags behind the fixation position (for about $500 \mathrm{~ms}$ or up to three words), a phenomenon that has been termed "eye-voice span" (Levin \& Buckler-Addis, 1979). In contrast, inner speech should exhibit a much smaller lag as the processing necessary to program and move the articulators (as a final aim of word processing in oral reading) is not required. From this view, it would make sense that no vowel length 
effect is seen on the target word when reading out loud, because this effect, seen in the silent condition when the word is being covertly articulated, is moved down stream. However, if this is the case, one would no longer expect a modulation of eye movements, since these are more closely bound to lexical access than to post-lexical processes to ensure efficiency of oculomotor control. Only in severe cases (e.g., ambiguity or comprehension problems), post-lexical processes are known to affect oculomotor control (e.g., by launching a regression back to previously inspected text, see Rayner, 1998). The finding that the processing of words $\mathrm{N}+1$ and $\mathrm{N}+2$ was not affected by the vowel length manipulation on the target word is thus in line with this interpretation. However, while the vowel length effect may be moved down stream in oral reading, this should not be the case in the articulatory suppression condition (Experiment 3), where articulation was not related to the written words. However, there was still no vowel length effect in Experiment 3, which renders an explanation in terms of a temporal postponement of the effect in oral reading rather unlikely.

Based on the results of Experiments 1 to 3 alone, one might have argued that any type of cognitive load induced by a secondary task demand beside reading may attenuate effects of vowel length processing. However, the results of Experiment 4 effectively ruled out a general cognitive load explanation as an alternative to the more specific inner speech explanation.

Another (related) alternative explanation for the modulation of the vowel length effect across experiments might refer to differences in overall difficulty between experimental conditions. However, the cross-experiment comparison provided empirical evidence against this alternative explanation. Neither reading speed (sentence reading times) nor comprehension was consistently lower in both the second and third experiment. Instead, there was no clear evidence for a severe disruption of the reading process in any experimental condition (including articulatory suppression). This indicates that phonological processing in general and phonetic processing in particular do not seem to be necessary prerequisites for lexical access during reading, but rather provide additional information to increase reading efficiency. Thus, phonological information processing does not seem to represent the primary route to word identification. In line with this assumption, studies of Daneman and Reingold (1993, 2000) suggest that orthography rather than phonological phonological information is normally used for lexical access. Dual-route models of word processing state that word meanings are generated either through a direct visual route or a phonological route, the latter implying an additional grapheme-phoneme conversion stage that extends processing duration. Therefore, the phonological route is primarily supposed to be used by unskilled readers or when words are unfamiliar (Coltheart et al., 2001). Although this latter view is at odds with numerous demonstrations of phonological processing in skilled reading (e.g., Lukatela \& Turvey, 1993; Pollatsek et al., 1992; Van Orden, 1987), phonological codes might generally only be an epiphenomenal by-product of word perception.

\section{Comparison with Previous Vowel Length Studies}

It appears interesting to compare the present results with previous data from tasks involving the processing of isolated words. Lukatela et al. (2004) found a vowel length effect in lexical decision task, but this effect was attenuated in a word naming task. Word naming resembles oral reading in that both tasks involve the pronunciation of written words. Thus, a reduced vowel length effect in word naming is clearly compatible with the data from Experiment 2. However, Lukatela et al. also reported a significant vowel length effect on lexical decision times under articulatory suppression demands, which is not compatible with the results from Experiment 3 . Probably, the overall difference between lexical decision and natural sentence reading is too great, and the underlying cognitive mechanisms may differ considerably. Additionally, it is important to note that in the English spelling system (used in the previous lexical decision studies by Abramson \& Goldinger, 1996, and Lukatela et al., 2004), a given vowel spelling can correspond to a variety of phonemes, whereas this is not the case in the more regular German orthography (e.g., Landerl, Frith, \& Wimmer, 1996; Wolf et al., 1994). As a consequence, reading English should impose a higher demand on phonological processing than reading German. It is therefore possible that the extent to which phonological information is used for lexical access varies across languages. 


\section{A Three-stage Framework of Phonological Process- ing During Reading}

Experiment 2 and 3 suggest that the phonetic representations in reading are no unitary entity, but consist of input-related phonetic codes (strongly associated with inner speech) relevant for lexical access and outputrelated phonetic codes (for articulation purposes). Experiment 2 introduced the necessity for activating outputrelated phonetic codes (via the oral reading instruction), and if input- and output-related phonetic codes were identical, one would have expected an even greater vowel length effect in Experiment 2, which was not observed. However, it is possible that a common limited-capacity phonetic processing module is responsible for both, inputand output-related phonetic codes. Whenever articulation is needed, no resources might be left for the development of input-related codes.

With respect to phonological processing during reading in general, the present results nicely fit into a larger three-stage framework that can be derived from previous studies. First, phonological information about vowels is already acquired parafoveally, before a word is actually fixated (Ashby et al., 2006). This early pre-lexical phonological representation might be used for lexical access, but is enriched by additional phonetic information (e.g., stress assignment, vowel length) within the second stage of phonological processing. This claim is supported by previous single word studies (Lukatela et al., 2004) and reading studies (Ashby \& Clifton, 2005). The vowel length effects on gaze durations in silent reading demonstrated in the present study corroborate these results. This input-related representation is likely the basis of inner speech during silent reading. The second stage is assumed to be completed at the end of lexical access. After completion of lexical access, new output-related phonological codes may be activated for a transfer into working memory (e.g., later text integration purposes) or for subsequent pronunciation (oral reading). Given the overall speed of reading, these processing streams are likely to occur in parallel for several words at a time. Whereas the first two processing stages seem to influence oculomotor control in reading, the third (post-lexical) stage seems to have no substantial impact on fixation parameters. Taken together, these assumptions are in line with current models of eye movement control in reading, regardless of whether they posit a direct (Reichle et al., 2003) or a more indirect (e.g., Engbert, Nuthmann, Richter, \& Kliegl, 2005; Reilly
\& Radach, 2006) influence of lexical processing on eye guidance.

\section{Acknowledgements}

This article is dedicated to the memory of Dieter Heller (1945-2003), former professor of psychology at RWTH Aachen, who had a keen interest in phonological aspects of reading and strongly supported this line of work.

I would like to thank Christiane Schmitten for her help in the collection of suitable target words and those who kindly volunteered to participate in the study. Furthermore, I would like to thank Ralph Radach and two anonymous reviewers for helpful comments on earlier drafts of this paper. Correspondence concerning this article should be addressed to Lynn Huestegge, Institute for Psychology, RWTH Aachen University, Aachen, Germany. E-mail: lynn.huestegge@psych.rwth-aachen.de

\section{References}

Abramson, M., \& Goldinger, S. (1997). What the reader's eye tells the mind's ear: Silent reading activates inner speech. Perception \& Psychophysics, 59, 1059-1068.

Ashby, J., \& Clifton, C. (2005). The prosodic property of lexical stress affects eye movements during silent reading. Cognition, 96, 89-100.

Ashby, J., Treiman, R., Kessler, B., \& Rayner, K. (2006). Vowel processing during silent reading: Evidence from eye movements. Journal of Experimental Psychology: Learning, Memory, \& Cognition, 32, 416424.

Baayen, R. H., Piepenbrock, R., \& Gulikers, L. (1995). The CELEX lexical database (Release 2) [CD-ROM]. Philadelphia: Linguistic Data Consortium, University of Pennsylvania [Distributor].

Baddeley, A. D., Lewis, V. J., \& Vallar, G. (1984). Exploring the articulatory loop. Quarterly Journal of Experimental Psychology: Human Experimental Psychology, 36(A), 233-252.

Baddeley, A. D., Thomson, N., \& Buchanan, M. (1975). Word length and the structure of short-term memory. Journal of Verbal Learning \& Verbal Behavior, 14, 575-589. 
Berent, I., \& Perfetti, C. A. (1995). A rose is a REEZ: The two-cycles model of phonological assembly in reading English. Psychological Review, 102, 146-184.

Browman, C., \& Goldstein, L. (1995). Dynamics and articulatory phonology. In R. Port \& T. van Gelder (Eds.), Mind as motion: Explorations in the dynamics of cognition (pp. 175-193). Cambridge, MA: MIT Press.

Brown, R. (1958). Words and things: An introduction to language. New York: Free Press.

Chomsky, N., \& Halle, M. (1968). The Sound Pattern of English. New York: Harper \& Row.

Coltheart, M., Rastle, K., Perry, C., Langdon, R., \& Ziegler, J. (2001). DRC: A dual route cascaded model of visual word recognition and reading aloud. Psychological Review, 108, 204-256.

Daneman, M., \& Reingold, E. M. (1993). What eye fixations tell us about phonological recoding during reading. Canadian Journal of Experimental Psychology, 47, 153-178.

Daneman, M., \& Reingold, E. M. (2000). Do readers use phonological codes to activate word meanings? Evidence from eye movements. In A. Kennedy, R. Radach, D. Heller \& J. Pynte (Eds), Reading as a perceptual process (pp. 447-473). Amsterdam: Elsevier.

Drieghe, D., \& Brysbaert, M. (2002). Strategic effects in associative priming with words, homophones, and pseudohomophones. Journal of Experimental Psychology: Learning, Memory, and Cognition, 28, 951961.

Egger, V. (1904). La parole intérieure: Essai de psychologie descriptive. Thèse présenté à la Faculté des Lettres de Paris par Victor Egger [Inner speech: An experiment of descriptive psychology. Thesis presented by Victor Egger to the Faculté des Lettres, Paris] (2nd ed.). Paris: Alcan.

Engbert, R., Nuthmann, A., Richter, E.M., \& Kliegl, R. (2005). SWIFT: a dynamical model of saccade generation during reading. Psychological Review, 112, 777-813.

Fodor, J. D. (1998). Learning to parse? Journal of Psycholinguistic Research, 27, 285-319.

Folk, J. R. (1999). Phonological codes are used to access the lexicon during silent reading. Journal of Experi- mental Psychology: Learning, Memory, and Cognition, 25, 892-906.

Fredriksen, J., \& Kroll, J. (1976). Spelling and sound: Approaches to the internal lexicon. Journal of Experimental Psychology: Human Perception \& Performance, 2, 361-379.

Frost, R. (1998). Toward a strong phonological theory of visual word recognition: True issues and false trails. Psychological Bulletin, 123, 71-99.

Heller, D. (1982). Eye movements in reading. In R. Groner \& P. Fraisse (Eds.), Cognition and eye movements (pp. 139-154). Amsterdam: North Holland.

Hendriks, A. W., \& Kolk, H. H. J. (1997). Strategic control in developmental dyslexia. Cognitive Neuropsychology, 14, 321-366.

Huey, E. B. (1908/1968). The psychology and pedagogy of reading. Cambridge, MA: MIT Press.

Jared, D., \& Seidenberg, M. S. (1990). Naming multisyllabic words. Journal of Experimental Psychology: Human Perception and Performance, 16, 92-105.

Kenstowicz, M., \& Kisserberth, C. (1979). Generative phonology. New York: Academic Press.

Klapp, S. T. (1971). Implicit speech inferred from response latencies in same-different decisions. Journal of Experimental Psychology, 91, 262-267.

Landerl, K., Frith, U., \& Wimmer, H. (1996). Intrusion of orthographic knowledge on phoneme awareness: Strong in normal readers, weak in dyslexic readers. Applied Psycholinguistics, 17, 1-14.

Lee, Y.-A., Binder, K. S., Kim, J. O., Pollatsek, A., \& Rayner, K. (1999). Activation of phonological codes during eye fixations in reading. Journal of Experimental Psychology: Human Perception and Performance, 25, 948-964.

Levin, H., \& Buckler-Addis, A. (1979). The eye-voice span. Cambridge, MA: MIT Press.

Liu, W., Inhoff, A. W., Ye, Y., \& Wu, C. (2002). Use of parafoveally visible characters during the reading of Chinese sentences. Journal of Experimental Psychology: Human Perception and Performance, 28, 12131227.

Lukatela, J., Eaton, T., Sabadini, L., \& Turvey, M.T. (2004). Vowel duration affects visual word identification: Evidence that the mediating phonology is pho- 
netically informed, Journal of Experimental Psychology: Human Perception and Performance 30, 151162.

Lukatela, G., \& Turvey, M. T. (1994). Visual access is initially phonological: I. Evidence from associative priming by words, homophones, and pseudohomophones. Journal of Experimental Psychology: General, 123, 107-128.

McCusker, L., Hillinger, M., \& Bias, R. (1981). Phonological recoding and reading. Psychological Bulletin, 89, 217-245.

McCutchen, D., \& Perfetti, C. (1982). The visual tonguetwister effect: Phonological activation in silent reading. Journal of Verbal Learning \& Verbal Behavior, 21, 672-687.

Meyer, D. E., Schvaneveldt, R. W., \& Ruddy, M. G. (1974). Functions of graphemic and phonemic codes in visual word recognition. Memory \& Cognition, 2, 309321.

Miellet, S., \& Sparrow, L. (2004). Phonological codes are assembled before word fixation: Evidence from boundary paradigm in sentence reading. Brain and Language, 90, 299-310.

Perfetti, C. A., \& Bell, L. C. (1991). Phonemic activation during the first $40 \mathrm{~ms}$ of word identification: Evidence from backward masking and priming. Journal of Memory and Language, 30, 473-485.

Perfetti, C. A., Zhang, S., \& Berent, I. (1992). Reading in English and Chinese: Evidence for a "universal" phonological principle. In R. Frost \& L. Katz (Eds.), Orthography, phonology, morphology, and meaning (pp. 227-248). Amsterdam: North-Holland.

Pollatsek, A., Lesch, M. F., Morris, R. K., \& Rayner, K. (1992). Phonological codes are used in integrating information across saccades in word identification and reading. Journal of Experimental Psychology: Human Perception and Performance, 18, 148-162.

Pollatsek, A., Tan, L. H., \& Rayner, K. (2000). The role of phonological codes in integrating information across saccadic eye movements in Chinese character identification. Journal of Experimental Psychology: Human Perception and Performance, 26, 607-633.

Rayner. K. (1998). Eye movements in reading and information processing: 20 years of research. Psychological Bulletin, 124, 372-422.
Rayner, K., \& Duffy, S. A. (1986). Lexical complexity and fixation times in reading: Effects of word frequency, verb complexity, and lexical ambiguity. Memory and Cognition, 14, 191-201.

Rayner, K., Pollatsek, A., \& Binder, K. S. (1998). Phonological codes and eye movements in reading. Journal of Experimental Psychology: Learning, Memory, and Cognition, 24, 476-497.

Reichle, E., Rayner, K., \& Pollatsek, A. (2003). The E-Z Reader model of eye movement control in reading: Comparisons to other models. Behavioral and Brain Sciences, 26, 445-526.

Reilly, R., \& Radach, R. (2006). Some empirical tests of an interactive activation model of eye movement control in reading. Cognitive Systems Research, 7, 34-55.

Slowiaczek, M. L., \& Clifton, C. Jr. (1980). Subvocalization and reading for meaning. Journal of Verbal Learning and Verbal Behavior, 19, 573-582.

Spoehr, K., \& Smith, E. (1971). The role of orthographic and phonotactic rules in perceiving letter patterns. Journal of Experimental Psychology: Human Perception \& Performance, 104, 21-34.

Van Orden, G. C. (1987). A ROWS is a ROSE: Spelling, sound, and reading. Memory \& Cognition, 15, 181198.

Waters, G. S., Komoda, M.K., \& Arbuckle, T.Y. (1985). The effects of concurrent tasks on reading: Implications for phonological recoding. Journal of Memory and Language, 24, 27-45.

Wolf, M., Pfeil, C., Lotz, R., \& Biddle, K. 1994. Towards a more universal understanding of the developmental dyslexias: the contribution of orthographic factors. In V.W. Berninger (Ed.). The varieties of orthographic knowledge 1: Theoretical and developmental issues (pp. 137-171). Dordrecht: Kluwer.

Ziegler, J. C., Ferrand, L., Jacobs, A. M., Rey, A., \& Grainger, J. (2000). Visual and phonological codes in letter and word recognition: Evidence from incremental priming. Quarterly Journal of Experimental Psychology: Human Experimental Psychology, 53(A), 671-692. 